\title{
Development of a Prototype Autonomous Electric Vehicle
}

\author{
Aisha Abdul Mohammed ${ }^{1}$, Aliyu Abdullahi², Amina Ibrahim ${ }^{3}$ \\ 1, 2,3 Department of Electrical Engineering, Kaduna Polytechnic, Kaduna, Nigeria \\ Email: aishagarba585@gmail.com, aliyuabdullahi589@gmail.com, umaisha2us@gmail.com
}

\begin{abstract}
The paper presents an Autonomous Electric Vehicle with obstacle avoidance system. This research work made use of ultrasonic sensors, the principle of distance measurements and calculations as well as detecting obstacle on its path. The device consists of three ultrasonic sensors that detect object for each left, right and front of the vehicle, based on developed and installed codes in the Arduino microcontroller and displays the range using ISIS Proteus 8 electronic modelling software. The minimum and maximum range of object detections is $2 \mathrm{~cm}$ to $400 \mathrm{~cm}$ respectively. However, the measured distance was from $25 \mathrm{~cm}$ to $150 \mathrm{~cm}$ and the corresponding calculated distances using oscilloscope waveforms are $28.10 \mathrm{~cm}$ and $148.3 \mathrm{~cm}$. The difference between the measured and calculated distance was $5.4 \%$ on average. GPS navigates the vehicle autonomously to its destination using an algorithm for navigation based on reactive behavior. The vehicle is powered by rechargeable batteries ( 4 lithium ion batteries) which are charged using external power source by connecting into electricity grid. Furthermore, a solar panel has been utilized as a secondary source of power to charge the batteries. This reduces the dependency of the vehicle on external power sources. The vehicle is capable of moving for about $20 \mathrm{~m}$ to and fro and avoiding obstacle on its path.
\end{abstract}

Keywords- Autonomous Electric Vehicle, Obstacle Avoidance System, Ultrasonic sensor, Arduino microcontroller, GPS Navigation, Rechargeable batteries

\section{INTRODUCTION}

An autonomous car or vehicle is also called a self-driving car or driverless car or robotic car. Whatever the name but the aim of the technology is the same [1]. Autonomous Vehicle (AV) research was accelerated through the Defense Advanced Research Projects Agency's (DARPA) Grand Challenges Program in the US in 2004 [2]. The challenges resulted in AVs capable of traversing dessert terrain in 2005, and in 2007. Researchers also managed to place AVs on urban roads through the DARPA's Urban Challenge Program [3]. AVs powered by autonomous technologies, without requiring human control are, according to many, just around the corner. And the implications are vast [4]. Recent advances in computational capabilities, both in terms of hardware and algorithms, communication architectures, and sensing and navigation devices have made it possible to develop autonomous systems that exhibit a high degree of reliability in their operation [5]. Thus Electric vehicles (EVs) are automobiles operated by an electric motor as a substitute for an Internal Combustion Engine (ICE). This is facilitated by the incorporation of engines that use stored energy in batteries that are frequently loaded in electrical power supply (generally $240 \mathrm{~V}$ ) to operate these cars. EVs are therefore referred to as cars with zero emissions (ZEVs). Generally speaking, most EVs have fewer moving parts and require minimal maintenance; no oil change, overhaul or timing requires, and no exhaust is required. In perspective of the above, it could be said that EVs with their very quiet operation are much more energy effective than gasoline motors [6].

In developing an autonomous electric vehicle, navigation of the vehicle has been the most basic and yet most challenging task. This is because moving the vehicle to the desired place is priority as it moves, hence navigation become useful in any design of a moving vehicle especially for outdoor application where automatic supervision is needed, for example, in places where it might be risky for humans to be. Fully autonomous vehicles are being researched and developed such as the Google driverless car, cyber cars in the frame work of European projects [7], automated vehicles in the A utopia program [8], and vehicles targeted for competitions, like the DARPA Urban challenge [9] and DARPA Grand challenge [10].

A Global Positioning System (GPS) receiver had become a significant breakthrough in the development of moving vehicles. Around 1990, the GPS became available in a limited capacity for civilian use, and the possibility of rapid and accurate vehicle location and navigation sparked a flurry of activity. In 1995, the system reached full operational capability [11]. The advent of the GPS has afforded Autonomous Vehicle systems engineers a powerful new means of obtaining accurate navigation data that is required for precise tracking of given inertial trajectories [12]. A simple GPS receiver with better accuracy provides an easy means of developing moving vehicles. However, since the GPS only provide the heading control and the global coordinates of a current location, it is required to implement a hardware and software system that can navigate the vehicle. The main advantage of using GPS is that the data gathered does not depend on previous readings and therefore errors in localization do not grow over the course of time.

However, studies have been done in order to tackle the limitations of GPS technology. One of them was the use of a map-based navigation for an outdoor environment [13]. The robots positioning is obtained using odometers and differential GPS (DGPS) measurements and an extended Kalman filtering framework is used to correct the positioning data. Through testing the authors found that even when DGPS position measurements were highly inaccurate, however, the heading data was still reliable. Though testing of the DGPS data still has to be done around areas with large natural obstructions like trees [14]. 
It is expected that Autonomous Vehicles represent more opportunities to develop innovative in-vehicle technology for entertainment or information purposes that will require a cockpit design adaptation and modification of the car controls for more flexibility of movement within the vehicle [15].

A number of methods for developing autonomous electric vehicles have been reported. For example, design of a simple autonomous electric vehicle that includes GPS-based navigation and uses ultrasonic sensors and image processing to prevent collision was made [16]. The deliverable product is a self-navigating unmanned vehicle that drives to userdefined destination coordinates that are transferred wirelessly to the vehicle. GPS and compass modules are used to navigate the vehicle while an efficient collision avoidance system is also being established. From the results obtained, the vehicle was able to detect nearby stationary or moving obstacles within $100 \mathrm{~cm}$ with the help of image processing; but the work utilizes battery sources only for power. Hence there is need to consider other power means.

Another method is by means of multi-beam Laser Imaging Detection and Ranging (LIDAR) sensor for surrounding reconstruction and obstacle detection [17]. The vehicle was able to drive autonomously from one waypoint to another using a GPS module. However, this approach has two limitations. One of them is that the sensor requires reconstruction before obstacle detection. Secondly, is limited to one source of power.

Other methods include development of intelligent electric vehicle for unmanned autonomous driving algorithm [18]. This intelligent electric vehicle directly controls traditional steering device and acceleration/brake pedals through electrical signals with electronic actuators which were equipped at each component. Also, various sensors were utilized to recognize surrounding situations, obstacles, and road boundary instead of human. The setback of this approach was that the system is expensive and obstacle avoidance is possible at a very close distance.

Development of Autonomous Smart Card to help people with carriage transportation such as luggage and groceries was also reported [19]. The autonomous vehicle was able to perform two main tasks such as following a user, and avoiding obstacles in real time. The setback of this approach was the lack of GPS to navigate autonomously and uses only battery source for power.

Lastly, it was reported that Electric Vehicle can be powered either by a single or multiple source combination and driven by a single or multiple algorithm [20]. From the output acquired, the vehicle can be driven by either a single or a combination of multiple sources; however, the work centred on optimizing power management system and not navigation. Therefore, there is need for GPS navigation.

In this journal, three ultrasonic sensors that detect object for each left, right and front of the vehicle will be implemented, based on developed and installed codes in the Arduino microcontroller and displays the range using ISIS Proteus 8 electronic modelling software. Also, GPS receiver will be utilized to calculate the vehicle's position by precisely timing the signals sent by the GPS satellites. A marked improvement in this research is the use of rechargeable batteries to power the vehicle, and a solar panel has been implemented as a secondary source of power to charge the batteries.

\section{MATERIALS AND METHODS}

\section{A. System Description}

The basis of the method used in this paper is based on Figure 1. The description of each stage is stated under. Input Keyboard: This is the main driver circuit of the vehicle, by applying logic 1 to the microcontroller, dc power supply (Vcc) initiate the system. Global Positioning System (GPS) [21]: The GPS receiver calculates its position by precisely timing the signals sent by GPS satellites. The receiver utilizes the texts it gets to determine the travel time of each message and to calculate the receiver distance from each satellite. Ultrasonic distance sensor [22]-[24]: The ultrasonic range modules are used to calculate obstacle distance from the car. These sensors have a maximum range of $400 \mathrm{~cm}$ and maximum effectual angle of 150 [25]-[27] Each sensor is connected to AVR and power supply via a 4 pin wire connector. ATmega32 Microcontroller [28]: It is available in 40 pin dual inline package (DIP) and has modified Harvard RISC architecture. It contains 32 programmable input/output lines with USART and SPI ports. Atmega32 was selected because of its low cost, easy availability, reliability and compatibility with $\mathrm{C}$ language programs.

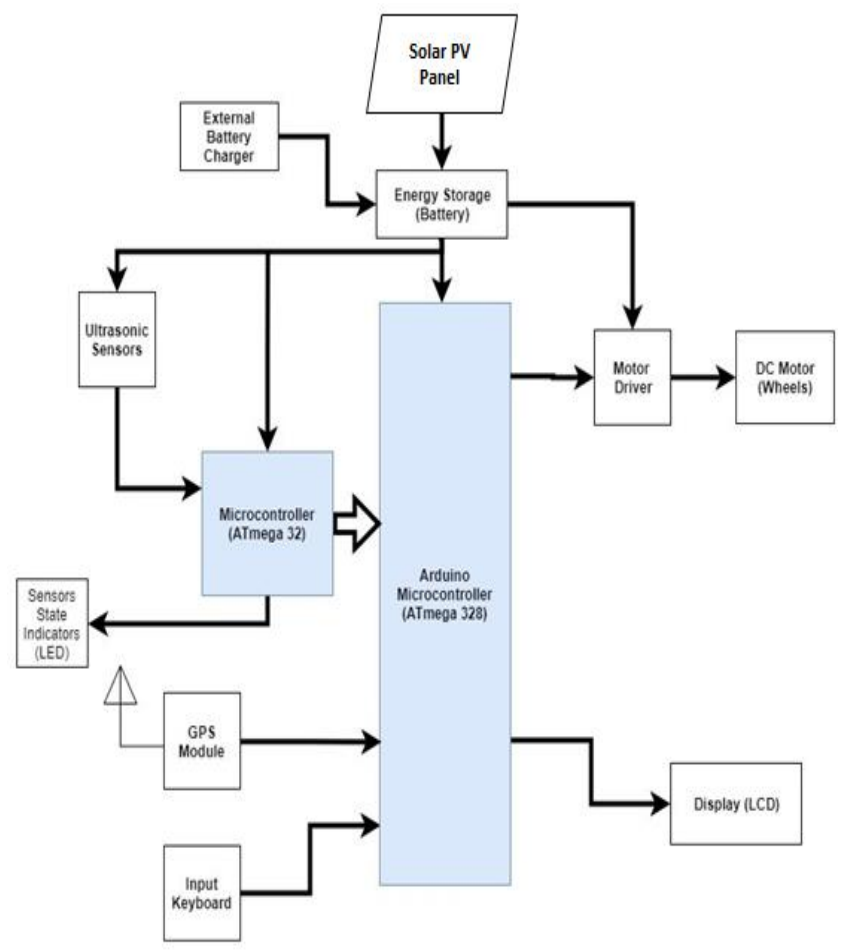

Fig. 1. Functional Block Diagram of an Autonomous Electric Vehicle

ATmega328 microcontroller [9]: The microcontroller is a DIP of 28 pins. It is a single chip created by Atmel 8-bit AVR RISC Base microcontroller that combines $32 \mathrm{kB}$ ISP Flash memory with read capacities while writing. Motor driver IC: L293D motor [30], [31] driver IC was used and acts as an interface between microprocessor in the vehicle and motors in the vehicle. The motor driver consists of two H-bridges and 
is the easiest circuit for managing a low-current control signal and then turning it into a higher-current signal that can drive the engine. DC Motors: These are electromechanical instruments that use the interaction of magnetic field and conductors to transform electrical energy into rotary mechanical energy. For traction purposes, a 5V DC motor was used for heading navigation. Liquid Crystal Display (LCD): LCD is an electronic display instrument that works by applying a variable electrical voltage to a layer of liquid glass, thereby causing changes in its optical characteristics. In this paper, LCD functions to display the longitude and latitude.

Light emitting diode (LED): LED is a semiconductor light source that emits light when current flows through it. It determines the sensor trigger when there is an object and to activate the vehicle brake. Energy storage battery: A 6V rechargeable Li-ion batteries are used to supply power to the autonomous electric vehicle, in which LM7805 voltage regulator was utilized to provide a constant voltage to charge the batteries during the day time. Solar panel: This is an instrument that utilizes photovoltaic effect, in order to convert radiation from the sun directly into electrical energy. It is a supplementary energy act as a backup when the battery runs down during the night. The solar cell used in the vehicle is multi-crystalline due to its faster rate of conversion of energy.

\section{B. System Hardware Design}

The system was designed in modules. The following modules can be identified from Figure 2: power supply, input interface, output interface and other supporting module.

Power Supply: A voltage regulator 7805 was used in the power supply to give precisely $5 \mathrm{~V}$ voltage and a maximum current of $1 \mathrm{~A}$, which is required by the microcontroller, HD44780 and the interface circuit. C1 and C2 were used to ensure good dynamic performance of the regulator. The maximum current in the ATMEGA $32 \& 328$ is $40 \mathrm{~mA}$, while the peak current required by the solar panel is $500 \mathrm{~mA}$. The maximum current demands from the rest of the sub-systems are as follows Crystal Oscillator 30mA, Ultrasonic Sensor $30 \mathrm{~mA}$, LCD 7mA, DC Motor 1\&2 300mA, and Motor driver IC $100 \mathrm{~mA}$.

Input Interface: This module consists of the ultrasonic sensor, dc motor $1 \& 2$, motor driver IC, port pull-up resistor (R1) and capacitors $(\mathrm{C} 1, \mathrm{C} 2)$ for crystal oscillator. The HC$\mathrm{SRO} 4$ ultrasonic sensor was used to determine the distance of an object due to its excellent non-contact range detection with high accuracy and stable readings in an easy-to-use package from $2 \mathrm{~cm}$ to $400 \mathrm{~cm}$.

Considering that the maximum output current sunk by any $\mathrm{I} / \mathrm{O}$ pin is $25 \mathrm{~mA}$; for safety one-tenth of the current $(2.5 \mathrm{~mA})$ is allowed to flow. Then calculating the resistance value gives by equation (1):

$$
\mathrm{R}_{1}=\frac{V}{I}=\frac{24}{2.5 \times 10^{3}}=9.6 \mathrm{k} \Omega
$$

Thus, R1 was chosen to be $10 \mathrm{k} \Omega$.
Dc motor 1\&2 was chosen for traction purposes, a 5V DC motor was used for heading navigation.

L293D motor driver IC was used to acts as an interface between microprocessor in the vehicle and motors in the vehicle for managing a low-current control signal and then turning it into a higher-current signal that can drive the engine.

The oscillator design requires the use of parallel cut crystal. Therefore, for a $4 \mathrm{Mz}$ crystal a $15 \mathrm{PF}$ capacitor is to be used for $\mathrm{C} 1$ and $\mathrm{C} 2$. Thus, a value of $22 \mathrm{PF}$ was selected for C3 and C4.

Output Interface: For the output components HD44780 was chosen due to its low power consumption, compact and light.

Other Modules: The ((MCLR)) ${ }^{-}$pin is tied up through a resistor R2. The recommended value is between $1 \mathrm{k} \Omega$ to $10 \mathrm{k} \Omega$. Therefore, a $10 \mathrm{k} \Omega$ resistor was chosen.

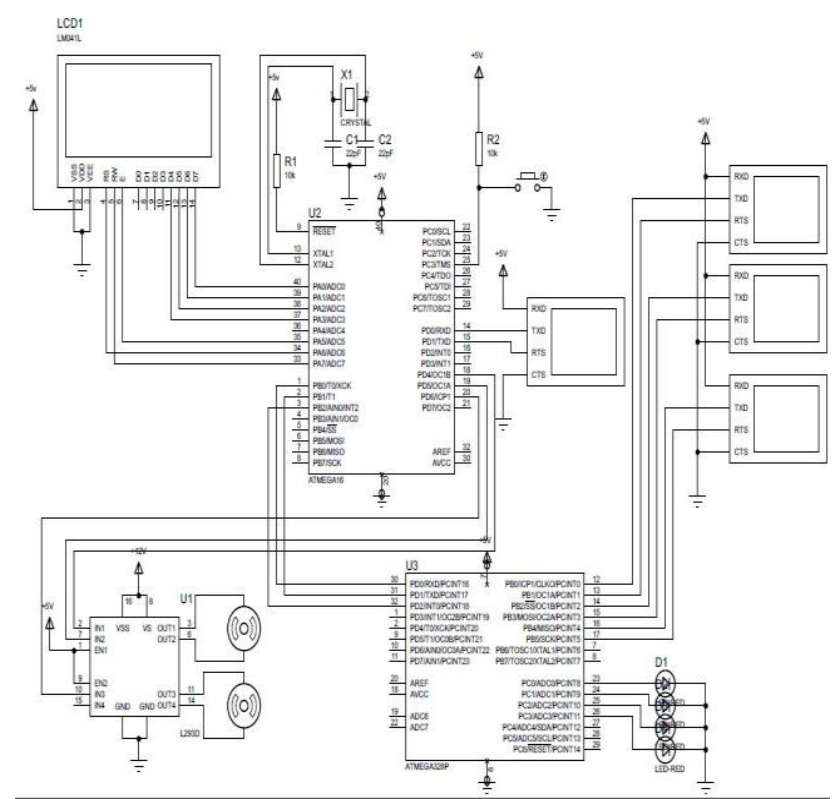

Fig. 2. Complete Circuit Diagram of a Proto-type Autonomous Electric Vehicle

\section{System Software Design}

The software design for the ATmega32 and ATmega328 were programmed using Micro $C$ in an MPLAB environment. The flow chart for the system is presented in Figure 3.

\section{RESULTS AND DISCUSSION}

Apart from the solar panel and mechanical parts (DC motor wheels and it base), all the components were arranged and soldered on a rectangular Vero board with dimension of $12 \mathrm{~cm} \times 8 \mathrm{~cm}$. Having done with the construction all components were tested for before the packaging. The picture of the whole assembly is as shown in Figure 4.

During communication sequence between the microcontroller and ultrasound of the system, all measured waveforms and test values showing the acquired results are illustrated in Figure 5-9, with oscilloscope settings at: Channel 1 Vertical knob at 200mV/div., Channel 2 Vertical knob at 500mV/div., and Horizontal knob at $5 \mathrm{~ms} / \mathrm{div}$. 


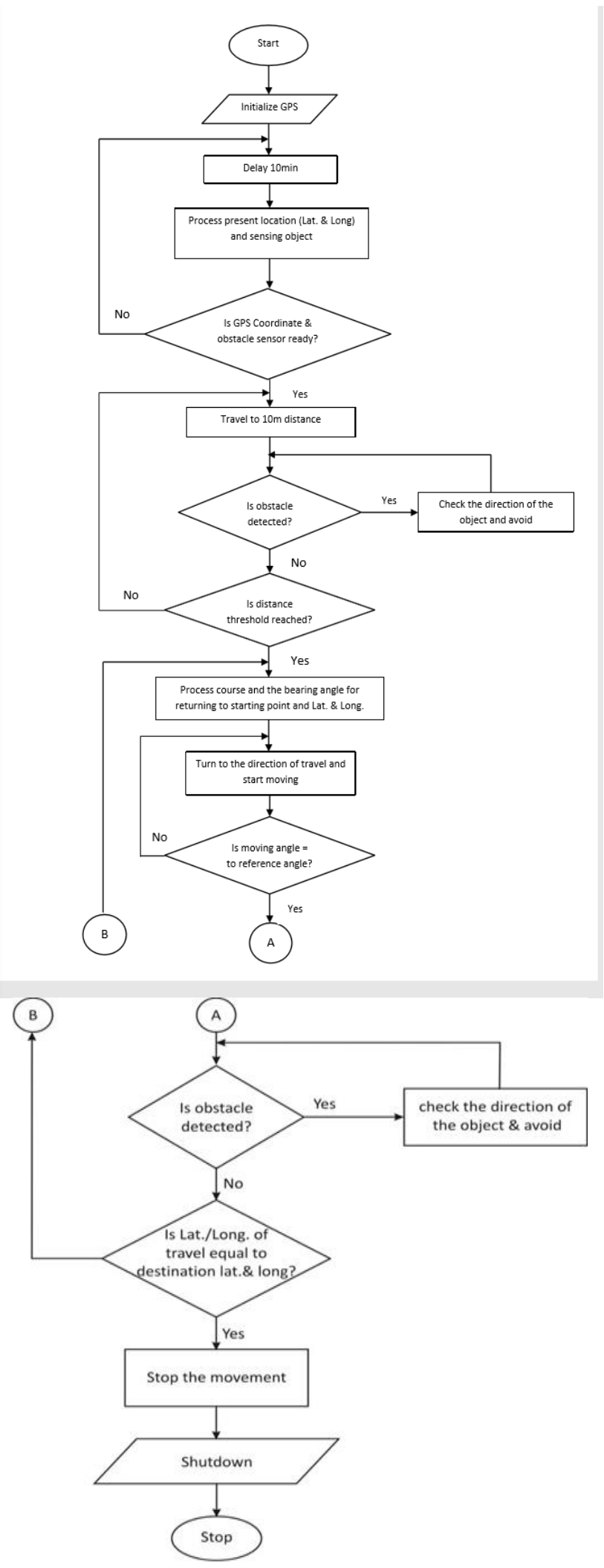

Fig. 3. Flowchart of the Algorithm for an Autonomous Electric Vehicle

The equation relating the return echo pulse width $(\tau)$ to the device calculated distance (d) is given by equation (2):

$$
\mathrm{d}=\frac{\tau(\mu s)}{58}
$$

A sample of the device calculated distance with reference to Figure 4 is as shown below:

Echo Pulse width, $\tau=0.326 \mathrm{div} \times 5 \mathrm{~ms} / \mathrm{div}=1.63 \mathrm{~ms}=$ $1630 \mu \mathrm{s}$.

Therefore, the device calculated distance in $\mathrm{cm}=\frac{1630}{58}=$ $28.10 \mathrm{~cm}$

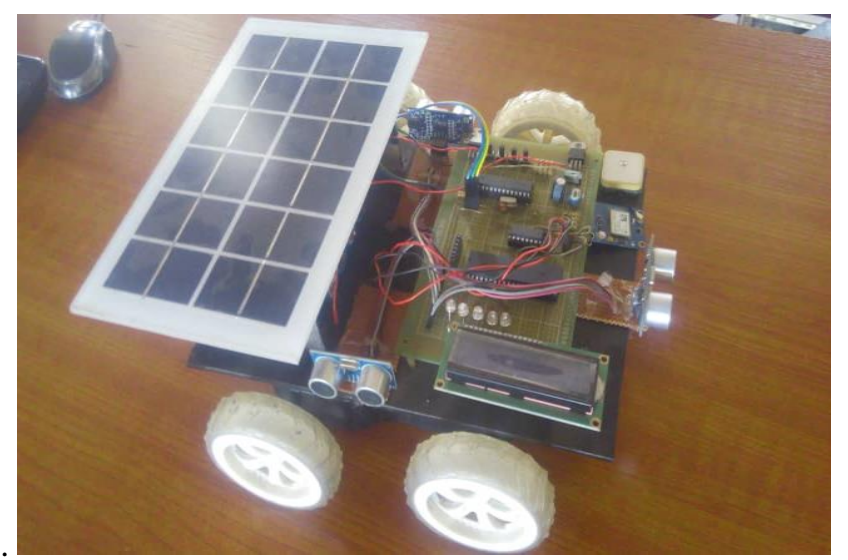

Fig. 4. A Proto-type Autonomous Electric Vehicle

Error analyses were performed between the devices calculated values and the measured (experimental) values using the formula of equation (3). The results were shown in Table 1.

$$
\text { Error }=\left|\frac{\text { experimental value-calculated value }}{\text { calculated value }}\right|
$$

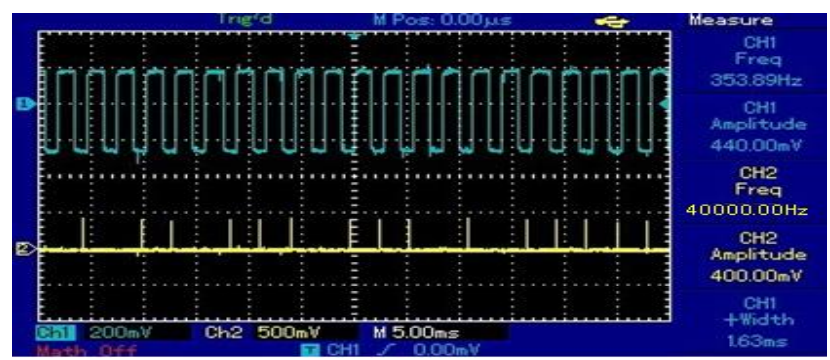

Fig. 5. Transmitted Signal \& Echo Signal Waveform at $25 \mathrm{~cm}$

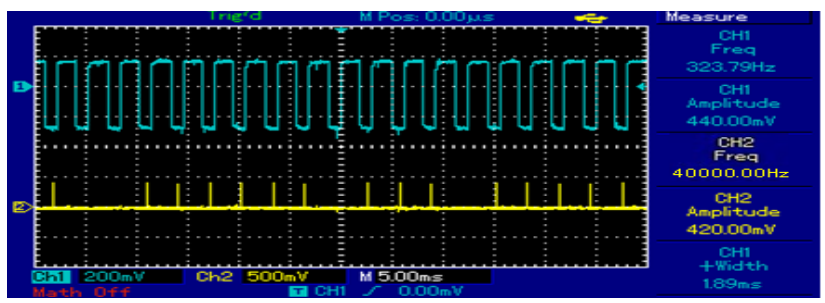

Fig. 6. Transmitted Signal \& Echo Signal Waveform at $30 \mathrm{~cm}$

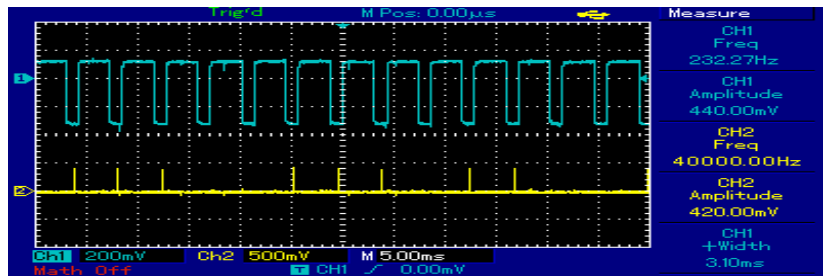

Fig. 7. Transmitted Signal \& Echo Signal Waveform at $50 \mathrm{~cm}$ 


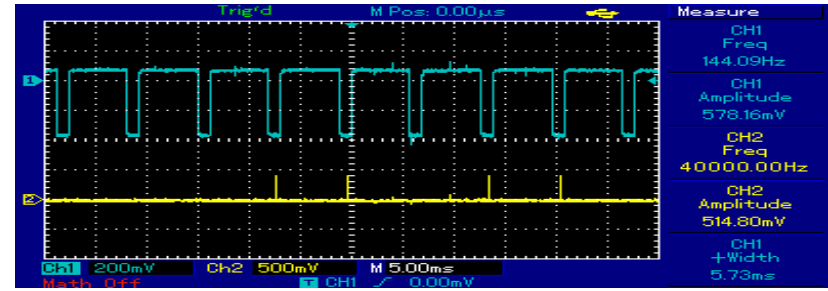

Fig. 8. Transmitted Signal \& Echo Signal Waveform at $100 \mathrm{~cm}$

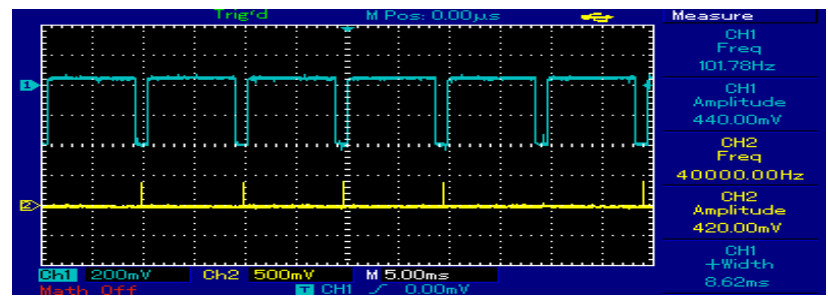

Fig. 9. A Proto-type Autonomous Electric Vehicle

From table 1 it can be seen that a distance of $25 \mathrm{~cm}$ is measured using an ultrasonic sensor of $28.10 \mathrm{~cm}$ with an echo pulse of 1630 and an error of $11.03 \%$. A distance of $30 \mathrm{~cm}$ was measured using an ultrasonic sensor of $32.76 \mathrm{~cm}$ with an echo pulse of 1900 and an error of $8.42 \%$. A distance of 50 $\mathrm{cm}$ was measured using an ultrasonic sensor of $51.72 \mathrm{~cm}$ with an echo pulse of 3000 and an error of $3.33 \%$. A distance of $100 \mathrm{~cm}$ was measured using an ultrasonic sensor of $99.14 \mathrm{~cm}$ with an echo pulse of 5750 and an error of $0.87 \%$. A distance of $150 \mathrm{~cm}$ was measured using an ultrasonic sensor of 148.3 $\mathrm{cm}$ with an echo pulse of 8600 and an error of $1.14 \%$.

TABLE I. Echo Pulse Width And Distance Measurement Data

\begin{tabular}{|l|l|l|l|}
\hline $\begin{array}{l}\text { Measured } \\
\text { distance }(\mathbf{c m})\end{array}$ & $\begin{array}{l}\text { Calculated } \\
\text { distance }(\mathbf{c m})\end{array}$ & $\begin{array}{l}\text { Echo Pulse } \\
\text { width }(\boldsymbol{\mu s})\end{array}$ & Error (\%) \\
\hline 25 & 28.10 & 1630 & 11.03 \\
\hline 30 & 32.76 & 1900 & 8.42 \\
\hline 50 & 51.72 & 3000 & 3.33 \\
\hline 100 & 99.14 & 5750 & 0.87 \\
\hline 150 & 148.3 & 8600 & 1.14 \\
\hline
\end{tabular}

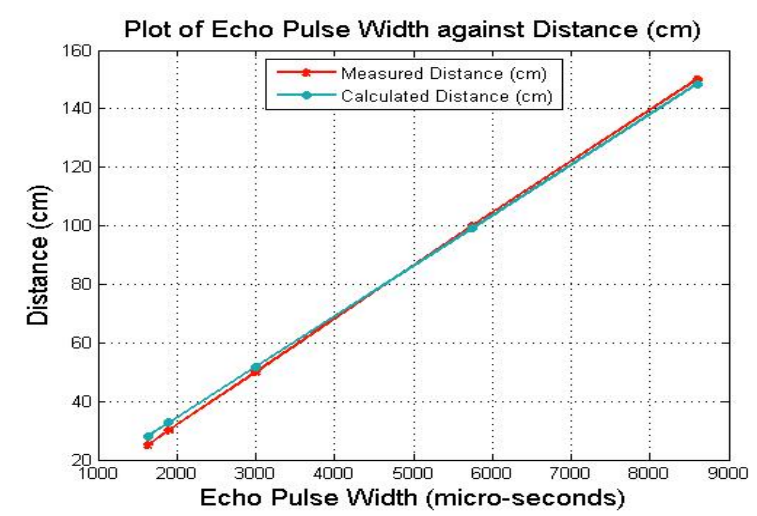

Fig. 10. The Graph of Echo Pulse Width versus Distance

From the graph shown in Figure 10, the measured and the calculated values are linearly dependent on the echo pulse width. Table 2 shows the results for obstacle avoidance test.

TABLE II.

\begin{tabular}{|l|l|l|l|l|l|}
\hline $\begin{array}{l}\text { Distance } \\
\text { covered } \\
(\mathrm{cm})\end{array}$ & $\begin{array}{l}\text { Assigned } \\
\text { threshold } \\
(\mathrm{cm})\end{array}$ & $\begin{array}{l}\text { Measured } \\
\text { threshold } \\
(\mathrm{cm})\end{array}$ & $\begin{array}{l}\text { Error } \\
(\%)\end{array}$ & \multicolumn{2}{|l|}{ GPS Position } \\
\cline { 5 - 7 }
\end{tabular}

\begin{tabular}{|l|l|l|l|l|l|}
\hline 29.6 & 30 & 30.5 & 1.67 & 7.407378 & 10.51901 \\
\hline 63.8 & 30 & 30.2 & 0.67 & 7.407384 & 10.51904 \\
\hline 81.7 & 30 & 30.3 & 1.00 & 7.407683 & 10.51965 \\
\hline 102.8 & 30 & 30.4 & 1.33 & 7.407801 & 10.51973 \\
\hline 138.7 & 30 & 30.3 & 1.33 & 7.407938 & 10.51989 \\
\hline
\end{tabular}

The data in Table 2 shows that as the distance covered by the electric vehicle increases, the GPS position (longitude and latitude) also increases. Besides, there are little discrepancies between the assigned and measured threshold values, where a maximum error of $1.67 \%$ was recorded.

\section{CONCLUSION}

An autonomous electric vehicle was implemented using ATmega32 and ATmega328 microcontroller. An additional feature is the use of ultrasonic sensor technology, possesses exceptional linearity, even over lengths up to 400 centimeters, with repeatability up to $0.002 \%$ of the measurement range. The vehicle is fully autonomous and after the initial loading of the code, it requires no user intervention during its operation. When placed in unknown environment with obstacles, it moved while avoiding all obstacles with considerable accuracy.

\section{REFERENCES}

[1] T.Raviteja, “An Introduction of Autonomous Vehicles and a Brief Survey”, Journal of Critical Reviews, vol. 7, no. 13, Pp 196-202, 2020.

[2] A.Faisal et al, "Understanding Autonomous Vehicles: A systematic literature review on capability, impact, planning and policy", The Journal of Transport and Land Use, vol. 12, no. 1, Pp 45-72, 2019.

[3] S.D. Pendleton et al, Perception, Planning, Control, and Coordination for Autonomous Vehicles, 2017.

[4] L.Porter, "The Autonomous Vehicle Revolution: Implication for Planning”, Planning Theory \& Practice Journal, vol. 19, no. 5, Pp 753-778, 2018.

[5] E.Frazzoli, et al, "Real-Time Motion Planning for Agile Autonomous Vehicles", Journal of Guidance, Control, and Dynamic, vol. 25, no. 1, Pp 116, 2002.

[6] R.Bansal, Electric Vehicles, Department of Electrical, Electronics and Computer Engineering, Birla Institute of Technology and Science, Pilani India. 2005.

[7] M.Parent, "Advance Urban Transport: Automation is on the Way", IEEE Intelligent System”, vol. 22(2), 2007.

[8] J.Perez, V. Milanes, E. Onieva, "Cascade Architecture for Lateral Control in Autonomous Vehicles", IEEE Transaction on Intelligent Transportation System ", vol. 12(1), Pp 73-82, 2011.

[9] C.Urmson, et al, “Autonomous Driving in Urban Environment: Boss and the Urban Challenge", Journal of Field Robotics: Special Issues on the 2007 DARPA Urban Challenge, Pp 425-466, 2008.

[10] S.Thrun, et al, "Winning the DARPA Grand Challenge", Journal of Field Robotics, 2006.

[11] I.Unal and M. Topakci, "Design of a Remote-controlled and GPSguided Autonomous Robot for Precision Farming", International Journal of Advance Robotic Systems, vol. 12, no. 194, 2015.

[12] I.Kaminer et al, "Trajectory Tracking for Autonomous Vehicles: An Integrated Approach to Guidance and Control", Journal of Guidance, Control and Dynamics, vol. 21, no. 1, Pp 29-38, 1998.

[13] O.Ohno, et al, "An Investigation into the long-term Excessive Deflection of PC Via", International Journal of Advance Robotic Systems, vol. 12, no. 194, 2015.

[14] A.El-Rabbany, Introduction to GPS: the Global Positioning System, 2nd Edition, Boston, 2006.

[15] O.M. Cristina,"Autonomous Vehicles and Smart Mobility Related Technologies", Info communications Journal, , Volume VIII, Number. 2, Pp 21, 2016. 
[16] H.Ejaz, "GPS Based Navigation and Collision Avoidance using Ultrasonic Sensors and Image Processing for Autonomous Vehicle", International Journal of Computer and Electronics Research, Vol. 3, Issue 4, August 2014.

[17] C. Fernadez, R. Dominguez, D. Fernandez-l-lorca and Miquel A., "Autonomous Navigation and Obstacle Avoidance of a Micro-Bus", International Journal of Advanced Robotic system, 2013

[18] I.Yub Kim et al, "Development of Intelligent Electric Vehicle for Study of Unmanned Autonomous Driving Algorithm", World Electric Vehicle Journal, Vol. 6, 2013.

[19] G. Leung et al, "Autonomous Smart Car", University of Victoria, 2005.

[20] A.Flah, S. Lassad, C. Mahmud, "Overview of Electric Vehicle Concepts and Power Management Strategies", International Conference of Science and Electrical Technologies of Maghreb, CISTEM2014, Tunisia. 2014.

[21] K. Tiwari, X. Xiao, A. Malik, and N. Y. Chong, "A unified framework for operational range estimation of mobile robots operating on a single discharge to avoid complete immobilization," Mechatronics, vol. 57, no. December 2018, pp. 173-187, Feb. 2019.

[22] Y. HU, J. HAO, W. YANG, C. GUO, and P. JIANG, "Motion point calculation method for robortic Ultrasonic Nondestructive Testing," in 2018 IEEE Far East NDT New Technology \& Application Forum (FENDT), 2018, pp. 85-89.

[23] R. R. Dam, H. Biswas, S. Barman, and A.-Q. Ahmed, "Determining 2D shape of object using ultrasonic sensor," in 2016 3rd International Conference on Electrical Engineering and Information Communication Technology (ICEEICT), 2016, pp. 1-5.

[24] R. Wang, L. Chen, J. Wang, P. Zhang, Q. Tan, and D. Pan, "Research on autonomous navigation of mobile robot based on multi ultrasonic sensor fusion," in 2018 IEEE 4th Information Technology and Mechatronics Engineering Conference (ITOEC), 2018, no. Itoec, pp. 720-725.

[25] R. Bahri, R. Boucetta, and S. Bel Hadj Ali Naoui, "An innovative ultrasonic position and velocity sensor for mobile robots," in 2018 International Conference on Advanced Systems and Electric Technologies (IC_ASET), 2018, pp. 403-408.

[26] Y. Liu et al., "Mobile Robot Localisation and Navigation Using LEGO NXT and Ultrasonic Sensor," in 2018 IEEE International Conference on Robotics and Biomimetics (ROBIO), 2018, pp. 1088-1093.

[27] Y. Shao, P. Chen, and T. Cao, "A Grid Projection Method Based on Ultrasonic Sensor for Parking Space Detection," in IGARSS 2018 2018 IEEE International Geoscience and Remote Sensing Symposium, 2018, vol. 2018-July, pp. 3378-3381.

[28] F. Y. C. Albert, C. H. S. Mason, C. K. J. Kiing, K. S. Ee, and K. W. Chan, "Remotely operated solar-powered mobile metal detector robot," Procedia Comput. Sci., vol. 42, no. C, pp. 232-239, 2014.

[29] K. Khade, R. Naik, and A. Patil, "Design of all color line follower sensor with auto calibration ability," in 2017 7th International Symposium on Embedded Computing and System Design (ISED), 2017, vol. 2018-Janua, pp. 1-5.

[30] H. U. Zaman, M. M. H. Bhuiyan, M. Ahmed, and S. . T. Aziz, “A novel design of line following robot with multifarious function ability," in 2016 International Conference on Microelectronics, Computing and Communications (MicroCom), 2016, vol. 1, pp. 15.

[31] A. Elawad, B. Hagadam, R. Hamed, and E. Hussein, "Design and implementation of robotic system to transport disabled people," in 2013 INTERNATIONAL CONFERENCE ON COMPUTING, ELECTRICAL AND ELECTRONIC ENGINEERING (ICCEEE), 2013, pp. 530-534. 